\title{
RUTHENIUM DETECTION BY XRF IN METAMORPHIC ROCKS
}

\author{
RODRÍGUEZ P., OMAR ${ }^{1}$, JORGE E, LOPEZ C ${ }^{2}$., MIKEL F. HURTADO M $^{3}$., PÉREZ M. \\ ANGIE $\mathrm{CH}^{4}$, MEJIA M., DANNA $\mathrm{B}^{5}$ \& MEJÍA M., JORGE $\mathbf{I}^{6}$ \\ ${ }^{1,2,3}$ Universidad Central. Ingeniería Electrónica \\ ${ }^{4,5}$ Fundación Universidad Autónoma de Colombia \\ ${ }^{6}$ Instituto de Hidrología, Meteorología y Adecuación de Tierras HIMAT
}

\begin{abstract}
The following report shows the experimental results of detecting $\mathrm{Ru}$ (ruthenium) element, in metamorphic rocks, found on different geographic areas of Colombian, performing X-ray fluorescence spectroscopy (XRF). After field work, developed by the group and in order to classify the different rock samples, obtained at the outputs from different Colombian areas (white beach in Santa Marta, Cartagena, Sierra Nevada de Santa Marta, Chicamocha's Canyon Santander and near Villa de Leyva Boyaca), in a particular group of samples (Chicamocha's Canyon Santander), was detected $R u$, by XRF a rare element in nature, but even more uncommon in this area.

KEYWORDS: Amphibolite, Feldspar, Gneiss \& Igneous Rocks
\end{abstract}

Received: Sep 01, 2017; Accepted: Sep 21, 2017; Published: Nov 04, 2017; Paper Id: IJEEERDEC20171

\section{INTRODUCTION}

Platinum, palladium, rhodium, osmium and ruthenium are used in oil refining, automotive industry, due mainly to their corrosion and acid resistance. These metals are scarcy in the crust, also in Colombian areas. For more than 2 years the formed work group conformed by environmental engineering students (Fundación Universidad Autonoma) and professors from Electronic Department (Universidad Central), have invested their efforts in classify and characterize crystals and rocks around Colombia, especially in semi-desert zones like Villa de Leyva, la Guajira and Chicamocha's canyon. One of the main objectives in this research work is related to find unclassified minerals, with $\mathrm{Ru}$ around Colombian areas, useful information to be use for Ingeominas, were performed XRF analysis and already well known purity precious stones analysis, used for local jewelers. A measurement element protocol was established, in order to identify clearly the samples collected.

\section{Theoretical Model}

When a sample is radiated with X-rays, it may happen that dispersed radiation has not energy loss (Rayleigh), or has loss (Compton), or if the energy is high enough a vacancy in certain atomic level, could be created (photoelectric effect). In the last case, the excited atomic level decays, due to fill out the previous vacancy for an electron that comes from a lower energy level, releasing certain energy in two different forms [1]:

- As X-ray photon, where the probability is represented, by fluorescence production.

- As a transferring process of a certain electron that, coming from a lower energy level, which is ejected from the atom and finally causing two vacancies (Auger effect). 
The XRF spectroscopy is based in the first phenomena, identifying and characterizing fluorescence lines. The intensity fluorescence radiation is defined as a function (I), that depends of variables like; incident beam wavelength $\lambda$, mass absorption coefficient $(\rho / \mu)$, and other variables, that in this case are not enough relevant, but at the same time is really important the energy pick function or spectral line.

$$
I(\lambda)=I_{o} f(\lambda, \rho, \mu, \ldots)
$$

Where, $I_{o}-$ is the initial monochromatic beam intensity?

Is well known that, the theoretical calculation of the absorbed radiation intensity by the sample could fit with Lamber-Beer law, using the case of composed materials, this function is calculated as:

$$
I(\lambda)=I_{o} \exp \left[-\left(\mu_{m} \lambda \frac{\rho x}{\cos \left(\theta_{i}\right)}\right)\right]
$$

Where: $\mu_{m}$-sample's mass coefficient; $\rho$ - Samples density; $\theta_{i}$ - incident beam angle, respect to the simple.

\section{Outside Work}

The first sample's group (50), collected randomly on Playa Blanca Santa Marta, showed an Epidotetype crystal using XRF analysis (see Figure. 1).

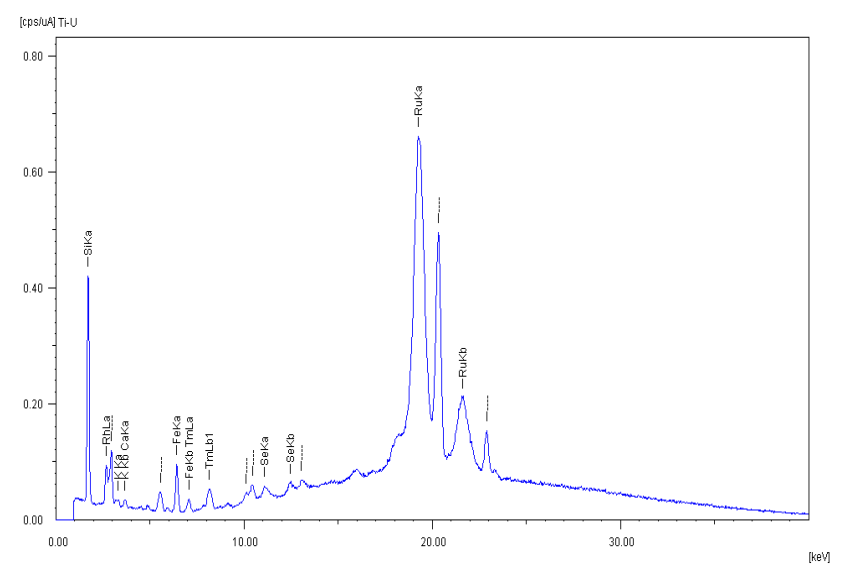

Figure 1: Epidote Sample XRF Spectrum. Sample from Playa Blanca Santa Marta Area

The sample analyzed in (figure. 1), corresponds a quartz like structure, which presents a slight mate shine on its surface, due to its highly silicon concentration $54.567 \%$, it may have been embedded in a little rock simple, together with the epidote mineral (greenish mineral), but at the same time presents traces of $\mathrm{Ru}$.

Other samples collected in the same place, but now Bornite type, do not show traces or significant Ru concentration, but a significant Fe concentration of $15,26 \%$ de Fe, as showed in figure 2 . 


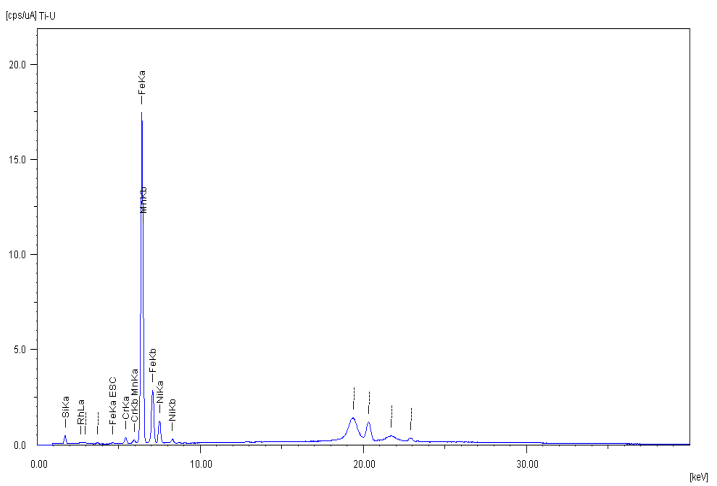

Figure 2: Bornite Sample XRF Spectrum. Sample from Playa Blanca Santa Marta Area

In other region of Colombian, in Chicamocha's canyon area (Santander), were analyzed samples mica schist like, with $42,86 \%$ of Si concentration, being evident the presence of mica (muscovite type) and biotite type structures. The XRF spectroscopy analysis is showed in figure 3.

The second set of samples (150), collected in other regions of Colombia mainly in Cauca, Amazonas and Cundinamarca were analyzed also by XRF. One particular sample was classified, as igneous volcanic rock, which presents the next XRF signals (see Figure. 4.)

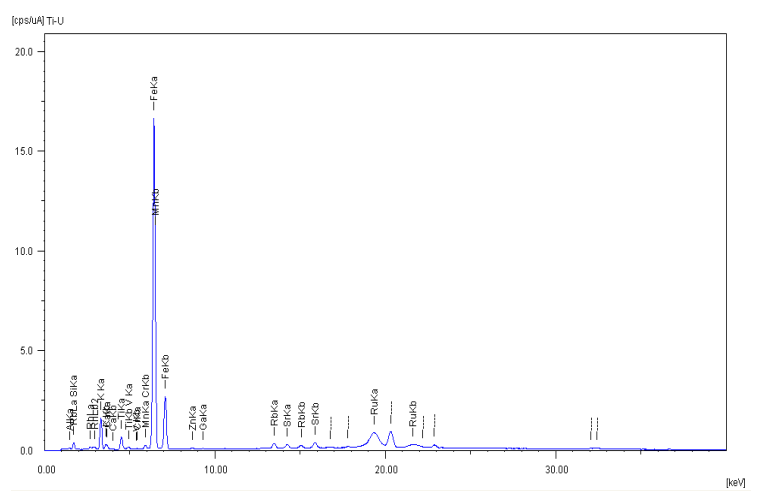

Figure 3: Mica Schist Sample XRF Spectrum. Sample from Chicamocha's Canyon (Santander) Area

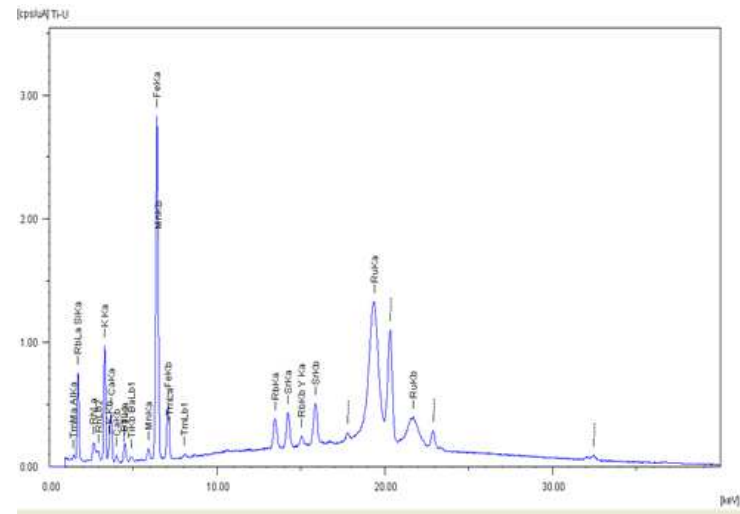

Figure 4: Igneous Volcanic Rock Sample XRF Spectrum Sample from Sopo-Cundinamarca 


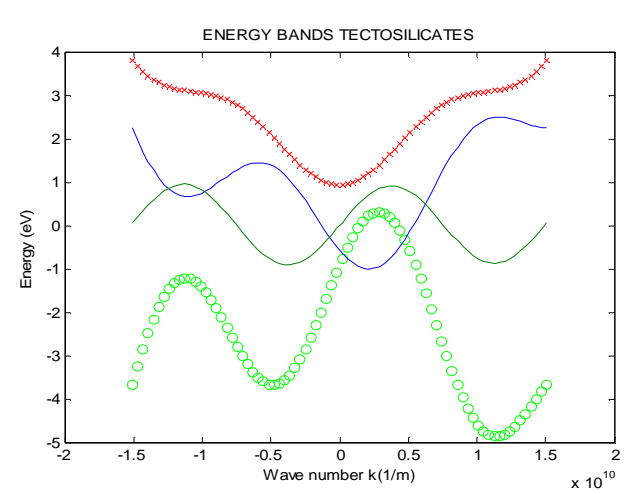

Figure 5: Simulated Behavior of Energy Bands of Tectosilicate Materials Dislocations. The Fermi Level (Green) Shows the Tendency of Energy Deformation Close to the Structural Dislocations in Presence of Ru

The $\mathrm{Ru}$ concentration in the previous samples, allows assuming the possible formation environment, when the results are compared with XRD Ru content patterns. The samples quartz type (Playa Blanca, Santa Marta area), is a special case, taking in to account the literature showed that, Ru content is characteristic from (1000-2000 ma.s.l), as the case of Ural Mountains, for this reason quartz samples were carried out, through of a transport process and erosion by means of a rock coming from a near place.

Last but not the least, one of the suggested problem, developed during this research report is related with energy bands behavior of studied materials (mostly tectosilicates), and even more in presence of Ru. The above mentioned behavior is showed in figure 5 .

\section{Electronic Measurement Model}

Taking in to account the information above, in the MAXWELL group laboratories, were designed an electronic device, that determines directly the apparent density of a studied sample, this measurement does not depend of sample shape, getting the mass coefficient sample directly.

The electronic device (capacitive system), takes a sinusoidal signal in the range of (35-130) KHz, with pick voltage of $5 \mathrm{~V}$, in a voltage DC data generated, by dipoles distribution in the local network of the rock, that realize different structures of the compound in the loss factor of the energy, due to a heat dissipation and X-ray absorption.

\section{CONCLUSIONS}

One of the most important contributions of this research work is the relation between the energy behaviors of tectosilicate materials (analyzed by XRF), in the presence of Ru and their structural dislocations. In terms of atomic transitions (Tectosilicate materials) is not direct and the transmission energy process is due, mainly by network vibrations and not for collision phenomena, due to beam energy incident.

As mentioned above, the Ru presence is evident mostly in Chicamocha's canyon (Santander), where the physical process of erosion and transport phenomena, allowed a certain grade of material detach with block sizes around (256 mm), guijón (64-256 mm), reaching the precise place; in a similar proportion were evident and the presence of Ru in a volcanic igneous rock, which confirms that, $\mathrm{Ru}$ comes from mountain's chains, mainly in ultramafic rocks, it means, in depths, where the change of metamorphic-igneous rock happens due to crystallization and fusion processes; however, it is necessary to do a new research project, that allowed us to stablish a possible source and generation of this rare and fascinating 
element.

This problem is open to be resolved, using more different rocks and be analyzed by XRF, with the main objective to determine sources or streaks with Ru content, in order to put this information on data bases of governmental institutes, mining companies or geographical classification entities, and be used to explore with highly control and efficiently, without causing environmental impacts.

\section{REFERENCES}

1. Bloch F. Z. Phys. 52, 555 (1928)

2. Mendez E., Bastard G., Physics Today. June 1993.

3. Joannopoulos J. D., Photonic Crystals. Princeton University Press. 1995

4. Brillouin L. Wave propagation in periodic structures. Dover. 1953

5. Waschke C.,Roskos H.,Schwedler R.,Leo K., Kurz H., P.R.L. 70, 3319 (1993)

6. $\quad$ Morandotti R., Peschel U., Aitchison J., P.R.L. 83, 4756 (1999)

7. Ben Dahan M., Peik E., Reichel J., Castin Y., Salomon C., P.R.L. 76, 4508 (1996)

8. Peschel U., Pertsch T., Lederer F., Optical Letters, 23, 1701 (1998)

9. T. Pertsch, P. Dannberg, W. Elflein, A Bräier., P.R.L 83, 4752 (1999)

10. Garcia-Pablos D., Sigalas M., Montero F., Torres M., P.R.L. 84, 4349 (2000)

11. Torres M., Montero de Espinosa F., Aragón J., P.R.L. 86, 4282 (2001)

12. Wannier G., Reviews of Modern Physics 34, 645 (1962)

13. D. K. Ferry \& S. M. Goodnick. Transport in nanostructures. Cambridge University Press, New York, 1997.

14. M. Gutzwiller. Chaos in classical and quantum mechanics. Spring-Verlag, New York, 1991.

15. Ang Hu and Yonghan Fang. Humidity Dependence on Apparent Dielectric Constant for DSP Cement Materials at High Frequencies. J. Am. Ceram. Soc., 82[7] 1741-47 (1999)

16. Unterweger, R. and Bergmeister, K. Investigations of Concrete Boreholes for Bonded Anchors. 2nd Int. PhD Symposium in Civil Engineering 1998 Budapest.

17. Bentz, Dale. P and et al. Influence of Cement Particle-Size Distribution on Early Age Autogenous Strains and Stresses in Cement-Based Materials. J. Am. Ceram. Soc., 84[1] 129-35 (2001)

18. Karlsson, Nils. A Study of a High-Resolution Linear Circuit for Capacitive Sensors. IEEE Transactions on Instrumentation and Measurement. Vol. 48. No. 6, December 1999.

19. Marchetti, B. and Revel, G. M. Medida en Línea de la Densidad en Crudo de Baldosas Cerámicas. Análisis de Incertidumbre. Castellón España. Qualicer 2002. P.GI-11P.GI-22

20. Manfredini, T and Novaes de Oliveira, A. P. Un Modelo para Predecir la Resistencia Mecánica de una Pieza Cerámica en Crudo. Castellón España Qualicer 96

21. Rodríguez, P. Omar. Cálculo del propagador de una onda electrónica incidente sobre un material amorfo.Revista Colombiana de Física, Vol., 34 No. 22002 
22. Serdyuk, Y. V., et al. Numerical Simulations and Experimental Study of Frequency - Dependent Dielectric Properties of Composite Material with Stochastic Structure. IEEE transactions on Dielectrics and Electrical Insulation. Vol. 11, No. 3, June 2004.

23. Du, Y., et al. Moisture and Temperature Effects on the Dielectric Spectrum of Transformer Pressboard. 2002 Annual Report Conference on Electrical Insulation and Dielectric Phenomena.

24. Duncan, J. C. and Marsh, R. D. L. Wide Frequency Range Dielectric Spectroscopy (Application to Food Materials). 1995 IEEE $5^{\text {th }}$ International Conference on Conduction and Breakdown in Solid Dielectrics.

25. Rodríguez P. Omar, Determinación de la influencia del factor estructural en el comportamiento de la permitividad relativa de materias primas cerámicas naturales bajo la acción de un campo eléctrico uniforme. XLIII Congreso de la Sociedad de Cerámica y Vidrio. Manises, 19 - 22 Noviembre de 2003 España.

26. Ducan J. Harris, et al. Novel exchange mechanisms in the surface diffusion of oxides. Letter to the editor. Journal of Physics: Condensed mater. 16 (2004) L187 - L192.

27. Kellog G. L. And Feibelmann P. J. Surface self - diffusion on PT (001) by an atomic exchange mechanism. 1990 Phys. Rev. Lett. 643147.

28. Tromp R. Novel exchange mechanisms in the surface diffusion oxides. 2003 Nat. Mater. 2212

29. Henkelman, G. and Jonsson, H. Surface diffusion atoms go underground. 2001. J. Chem. Phys. 115 - 9657. 